\title{
sciendo
}

\author{
Disputatio's Symposium on Berit Brogaard's Transient Truths \\ Oxford University Press, 2012

\section{On Two Arguments for Temporally Neutral Propositions}

\author{
Vasilis Tsompanidis \\ Institut Jean Nicod and \\ Instituto de Investigaciones Filosóficas, UNAM
}

DOI: 10.2478/disp-2013-0026

BIBLID [0873-626X (2013) 37; pp. 329-337]

In Transient Truths, Berit Brogaard 2012 offers a forcefully argued defense of what she calls 'temporalism': the view that many sentences express contents whose truth value can change over time. In recent years various arguments against temporalism have been posed by what seems to be the eternalist orthodoxy in analytic philosophy of language. I take Brogaard's book as the most complete and up-todate reply to the eternalist attacks. Hence, I bypass this discussion here to critically examine two self-standing arguments she offers directly against the eternalist, and for temporally neutral contents. Sections 1 and 3 argue that at the moment the arguments are not entirely successful, while section 2 expresses strong doubts over Brogaard's choice of sentences such as 'John is a firefighter' to motivate and exemplify her view.

\section{Disagreeing about occupations}

The first argument against the eternalist starts from the known difficulty eternalists have with conversations that take place over extended periods of time. According to Brogaard, 'most of these conversations are not about specific times but about some other subject matter altogether', a subject she takes to be 'temporally neutral' (2012: 66). Her paradigm conversation is the following:

\section{[FIRED_FIREFIGHTER]}

A: ... John is a firefighter

(Behind John's closed office door his superior is shouting 'You 
are fired!')

B: I guess you are right. But John is not a firefighter. He was just fired.

Brogaard explains that B's claim 'you are right' sounds odd, but the eternalist translation of the conversation (1' below) is perfectly fine. Hence the eternalist translation is mistaken.

(1') A says that John is a firefighter at $t_{1}$, and $B$ that he is not a firefighter at $t_{2}$.

Examples like [FIRED_FIREFIGHTER] seem an obvious problem for at least those eternalists that treat all present-tense verbs as referring strictly to the time instant when the sentence is uttered. The two conversants indeed seem to be talking about a more general subject matter. What could that be?

Well, it might be that they are talking about John's being a firefighter at least up to and including the time of their entire conversation. So when A utters

(1) John is a firefighter,

she might mean something like

$\left(1^{*}\right)$ John was a firefighter for some time before we started speaking, he is a firefighter now, and he will be a firefighter until at least we stop speaking.

If (A) means $(1 *)$ with her statement, B's retort 'I guess you are right' is actually wrong, since the last part of $\left(1^{*}\right)$ is not satisfied ${ }^{1}$. But now an eternalist can use $\left(1^{*}\right)$ to resist Brogaard's conclusion that the two conversants are sharing 'temporally neutral' information. (1*) is about a specific time interval, just a more complex one than it first

\footnotetext{
${ }^{1}$ There are of course real and difficult issues with specifying the exact meaning of phrases like 'you are right'. I will just note here the problematic use of a present-tensed form of the verb 'to be' in the phrase 'you are right': an insistent eternalist could reply that this is the exact issue the debate is trying to settle.
} 
appears.

Note that $\left(1^{*}\right)$ is not the claim that ' $\mathrm{B}$ can freely choose which time his assertions refer to' that Brogaard correctly criticizes in (2012: 68-69). The choice of reference time is not free, as it is always restricted by at least the term 'now'. Nor does $\left(1^{*}\right)$ contain the problematic claim that John is a firefighter at every time over an extended time interval. As Brogaard notes, this is a non-starter but can be avoided by taking the interval as basic, and not every time instant in it. And neither is $(1 *)$ the claim that the referred interval stretches unrestrictedly into the future, a claim rightly attacked by Brogaard in page 71 , since the time of $(1 *)$ is only supposed to stretch up until the point the conversations ends ${ }^{2}$. From the eternalist positions Brogaard mentions in her book, (1*) only comes close to the Salmon/Fitch intervalist positions, but it has some obvious restrictions on the referred interval that these positions do not seem to have, at least in the way Brogaard presents them.

\section{On simple present tense sentences}

There is one obvious drawback with (1*): it cannot be used as the final word on the semantics of every simple present-tense sentence. For example, it is not the intuitive analysis of the meaning of sentence 'John swims' truthfully uttered at a time when John is not actually swimming. In contrast, Brogaard's ultimate proposal in the last part of her book seems to offer a uniform treatment of sentences with verbs in the (grammatical) simple present tense. She claims, for example, that 'tensed sentences without time adverbials, when uttered at a particular time, do not make reference to the time of speech' (2012: 148), and, later, that 'temporal propositions are [...] the (natural) contents of simple present-tensed sentences without time adverbials' (2012: 155).

\footnotetext{
${ }^{2}$ There might of course exist presuppositions that the time referred can stretch more into the future - I return to this point in section 2. Incidentally, $(1 *)$ can be used for other sentences that Brogaard poses as problems for the eternalist, such as 'Mary loves me' (2012:42); [HAIR_SPLITTING] (72) and [FIRED_ AGAIN] (70).
} 
I will try to claim in this section that this issue might cut both ways. If it turns out that there is nothing simple about present tense sentences, and we have in our hands a case of widespread semantic polysemy or ambiguity that still needs to be investigated thoroughly, Brogaard's thesis can be denied. The eternalist could now reply that many of the intuitions and puzzles driving her case are there exactly because verbs in the present tense are ambiguous. Let me explain.

\subsection{Occupations}

I start with paradigm sentence (1) 'John is a firefighter'. It seems to me that there is not one reading of the sentence that conversants or philosophers of language can agree on, and that might form a stable basis of the agreement and disagreement intuitions Brogaard is after. A speaker can use (1) to talk about a person's current job (1a below), a person's past studies and intended occupation (1b), or even a person's 'call in life', what she and others define her as (1c):

(1a) John is a firefighter. He just now signed his contract with Firefighters United to fight fires.

(1b) John is a firefighter. He completed firefighter school in August and is now applying for jobs.

(1c) After 30 years with Firefighters United, John was fired last week and now works as a consultant. Despite that, he is, and always will be, a firefighter.

Each sentence above comes with its own temporal requirements, exactly because the properties we assign to John (current job, occupation, 'call-in-life') have different temporal lifespans. Accordingly, intuitions about 'believes that' sentences or possible conversational disagreements differ considerably. When we speak of current jobs, for example, we are very sensitive to the time of speech, while when we speak about an adult person's call-in-life we do not particularly care about it. 


\subsection{Being $x$}

The issue is not specific to sentence (1), but can be extended to every use of the verb 'to be'. This is quite evident when we move to a different language such as Spanish, which has two different copula verbs: 'ser' and 'estar'.

The verb 'ser' is used to assign stable properties to an entity or class of entities, as in (the Spanish translations of) (2a) - (2c).

(2a) Angela is German.

(2b) Kripke's piece is interesting. (2012: 47)

(2c) My phone number is 283-1759. (2012: 59)

These uses claim property stability over time- hence one could posit that they carry a semantic component, or pragmatic expectation, that the assigned property will be had by the entity for a long time in the future, or at least until very fundamental changes in the make-up of the entity take place. With 'ser', the eternalist $(1 *)$ reading I offered seems to me entirely appropriate.

In contrast, the verb 'estar' is used to assign temporary properties to an entity, such as location (3a), mood (3b), and current health (3c). It is also used for the present progressive as in English (3d).

(3a) MARY: I am in Boston. (2012: 46)

(3b) Vasilis is happy.

(3c) John is pale. (2012: 50)

(3d) John is swimming.

Here the standard eternalist translation tying the property attribution to the time of speech is closer to the meaning of the verb, and we might not even care about the property being part of the entity until the conversation ends. In these cases, however, eternalist meaning analyses such as (1') from section 1 are fine, and disagreement intuitions do not get off the ground. For example, the sentence

\footnotetext{
${ }^{3}$ Examples in italics are Brogaard's own examples to defend various claims for temporalism. For reasons of length, I do not get into how each example affects each claim, but a careful reader can do it if she so wishes.
} 
utterer can insist that she was right at the time of speech, no matter what has happened by the time her conversant actually responds.

\subsection{The present tense}

Besides the idiosyncrasies of the verb 'to be', similar issues can be posed concerning the ambiguity (or polysemy) of the present tense construction of the English language.

First, the present tense has what have been called 'habitual' uses $(4-6)$.

(4) Brit writes books.

(5) Mary loves me. (2012: 42)

(6) George is (works as) a summer tour operator.

Each of these sentences has at least one reading according to which the subject might not be $\varphi$-ing at exactly the time of the sentence's utterance, but has $\varphi$-ed with some regularity in the past, and is expected to carry on $\varphi$-ing in the future.

There are of course other uses of the present tense that might be taken to clearly, and only, indicate $\varphi$-ing at the time of utterance. And, at least in English, there are seemingly future-oriented uses of the present tense (7), and 'stable property assignation' uses (2a-c above).

(7) I'm giving a talk in Alaska. (2012: 154)

There might still exist more ambiguity or polysemy in the meaning of all tenses, to be revealed by further research in linguistics. My point here is simply that, given all this polysemy, it is too fast to claim that the (natural) contents of all the sentences I presented are temporal propositions. It might instead be that polysemy is exactly why the debate between eternalists and temporalists is puzzling, why we agree or disagree in specific examples, and why the eternalist 'translations' sometimes fail and other times sound incredibly obvious. ${ }^{4}$

${ }^{4}$ Note that Brogaard explicitly treats the term 'simple present tense' in her ultimate claims as denoting the 'grammatical present tense', not just one specific 
Admittedly, a strict instant-based eternalist fares badly with the uncovered ambiguities; but even she could reply that her analysis is reserved for only one kind of present-tense uses. And eternalists in general should be able to survive Brogaard's criticisms by positing different temporal intervals that a sentence can refer to, depending on the exact verb in the sentence, and the present-tense use it captures.

\section{Perception passes-on temporally neutral content}

I now turn to what seems to me the most forceful stand-alone argument against the eternalist that Brogaard offers in her essay ${ }^{5}$. It starts from the quite plausible premise that 'the phenomenology of perceptual experience determines the content of mental states' (2012: 177). But the phenomenology of perceptual experience does not seem to discriminate among different times (2012: 176). Hence, the content of some mental states cannot contain a specific time among its constituents, and is thus a 'temporal proposition'. There is a lot to be said about this novel and important argument — here I just offer two reasons to be suspicious of the second premise.

\section{1}

Take a simple statement such as (8) below, intended to capture my perceptual belief, or seeing-of, a red car in front of me.

(8) There is a red car in front of me.

Most of our perceptual experiences are reported with such statements, so it does not seem far-fetched to conclude that perceptual experiences do not discriminate among different times.

But perceptual experience is far richer in the temporal domain than (8) suggests. First, the perceiver automatically includes the percept in her present, since she can also report it by (9) below.

use of it. Hence her claims cover all my section 2 examples.

${ }^{5}$ I focus here on the 'perceptual experience' part of her 8.4 argument only. 
(9) There is now a red car in front of me.

In contrast to (8), (9) mentions a specific time, the one that 'now' refers to. One could argue just from this that some information about the specific time has to be part of the content of my perception, since (9) explicitly mentions it.

A perceiver always seems to know a lot about the temporal position of her percepts. I know, for example, that what I see is after my birth, concurrent with other percepts from the same or different modality, before or after others, and if a long time has passed since I registered it. That this happens ubiquitously in perception is shown by the fact that the information is easily recoverable — but it would not be if we just stored a 'temporal proposition' content such as (8) without any accompanying temporal data. Even if sometimes temporal phenomenology is very poor, by the time a perceptual belief is formed, it is put into a precise temporal position in the network of other past perceptions, current perceptions and desires, and future expectations. ${ }^{6}$ The point is that, despite (8) not mentioning all this information, and it seeming indeed not to discriminate among different times, some information about the specific time of my perception is passed on to our perceptual judgments by perception, and thus might also be part of the judgments' content.

\section{2}

A second reason to be suspicious of Brogaard's second premise is that perceptual beliefs often do not seem to explicitly represent locations or precise demonstrative information either. So one might be allowed to form an analogous claim to her second premise: that when I believe, say, in Santa Barbara, and then inside a similar room in Paris, what I would express with the statement

${ }^{6}$ It is important to note here, in response to Brogaard's similar argument in (2012: 58), that the brain does not need to store the time name, say 2:30pm, to keep track of the times of our perceptions. It only needs to store de re information that is specifically about that time. But then, pace Brogaard, the brain is a complex time-tracker, and, I should add, an incredibly efficient one at that. 
(10) It is really hot,

my perceptions do not discriminate among the two locations. Similarly for beliefs I would express with the statement 'this cat is pretty', when looking at extremely similar cats that I nevertheless know are different. But the fact that the expression of the perceptual belief does not seem to include some obvious differences in information between the two perceptual instances does not mean that the information is not part of the content of my perception or perceptual belief. After all, this is why we have demonstratives and indexicals, to be able to refer to different situations with the same cognitive apparatus.

At this point Brogaard could retort that, despite the fact that location and demonstrative information is sometimes not explicitly represented in the sentences I use to express my perceptions, it is phenomenally available. This is shown by the fact that I do distinguish between a belief expressed with (10) that I am having in Santa Barbara, and one I am having in Paris. But this is exactly the move that I made on behalf of the eternalist in 3.1: that some information (for the eternalist, information about a specific time) can be part of perceptual content, without that meaning that it is able to be 'read off' from the sentences the perceiver uses to report on her perceptions. If this is true, the phenomenology of perceptual experience does discriminate among different times, and Brogaard's argument for temporalism does not go through.

Vasilis Tsompanidis Institut Jean Nicod UMR 8129

Pavillon Jardin Ecole Normale Supérieure 29, rue d'Ulm F-75005 Paris tsompas@gmail.com 